\title{
A first report of a rare TP53 variant associated with Li-Fraumeni syndrome manifesting as invasive breast cancer and malignant solitary fibrous tumor
}

\author{
Juraj Prejac ${ }^{1,2}$, Natalija Dedić Plavetić ${ }^{1,3^{*}}$ (D) Kristina Gotovac Jerčić ${ }^{4}$ and Fran Borovečki ${ }^{4,5}$
}

\begin{abstract}
Background: Li-Fraumeni is a rare autosomal dominant cancer predisposition syndrome. The basis is a germline mutation of TP53 gene which encodes tumor suppressor protein resulting in early onset of tumors, most often breast cancer, soft tissue sarcomas, brain tumors, adrenocortical carcinomas, and leukemia.

Case report: We present a case of a young woman with a positive family history for cancer diagnosed with malignant solitary fibrous tumor and luminal B-like invasive breast cancer. Breast cancer and sarcomas account for the majority of tumors associated with Li-Fraumeni syndrome, yet solitary fibrous tumor is a rare clinical entity with no established guidelines for treatment. Even though both primary tumors were successfully resected, the sarcoma relapsed in the form of lung metastases. The NGS analysis revealed single nucleotide variant (c.1101-1G>A) in TP53 gene, affecting the acceptor splice site at intron 10. Until now, only one case of this genetic variant has been documented with conflicting interpretations of pathogenicity.

Conclusions: The knowledge of TP53 mutation status is essential since the management of these patients requires different approach to avoid excessive toxicity due to the risk of developing secondary malignancy. Using the clinical criteria to screen for affected individuals facilitates appropriate early genetic counseling of patients and their families. Following the American College of Medical Genetics criteria, we believe that the reported single nucleotide variant (c.1101-1G>A) in TP53 gene should be considered pathogenic.
\end{abstract}

Keywords: TP53, Li-Fraumeni syndrome, Invasive breast cancer, Malignant solitary fibrous tumor, Splice-site mutation

\footnotetext{
* Correspondence: ndedic@kbc-zagreb.hr

'Department of Oncology, University Hospital Centre Zagreb, Kišpatićeva 12,

10000 Zagreb, Croatia

${ }^{3}$ School of Medicine, University of Zagreb, Šalata 3, 10000 Zagreb, Croatia

Full list of author information is available at the end of the article
}

(c) The Author(s). 2021 Open Access This article is licensed under a Creative Commons Attribution 4.0 International License, which permits use, sharing, adaptation, distribution and reproduction in any medium or format, as long as you give appropriate credit to the original author(s) and the source, provide a link to the Creative Commons licence, and indicate if changes were made. The images or other third party material in this article are included in the article's Creative Commons licence, unless indicated otherwise in a credit line to the material. If material is not included in the article's Creative Commons licence and your intended use is not permitted by statutory regulation or exceeds the permitted use, you will need to obtain permission directly from the copyright holder. To view a copy of this licence, visit http://creativecommons.org/licenses/by/4.0/ The Creative Commons Public Domain Dedication waiver (http://creativecommons.org/publicdomain/zero/1.0/) applies to the data made available in this article, unless otherwise stated in a credit line to the data. 


\section{Background}

Li-Fraumeni syndrome (LFS) is an autosomal dominantinherited cancer predisposition syndrome characterized by high penetrance and early onset of malignancy [1]. The LFS was defined in 1988 by Frederick Li and Joseph Fraumeni from 24 families with inheritance of high susceptibility to malignant tumors before the age of 45 years [1]. Even though any type of neoplasm may occur, pre-menopausal breast cancer (BC) is observed in 79\% of females, followed by soft tissue sarcomas (STSs) in $27 \%$ of patients, osteosarcomas, central nervous system tumors, and adrenocortical carcinoma [2]. Germline mutation in the TP53 gene which encodes tumor suppressor protein p53 is the basis of LFS [3, 4]. Over $50 \%$ of all tumors exhibit somatic mutation in TP53 making it the most frequent target for mutation in human cancer [5]. Considering its role in suppression of carcinogenesis, the risk of cancer development in TP53 mutation carriers was initially calculated to be $50 \%$ before the age of 30 [6]. A more recent conservative approach estimates the prevalence of pathogenic and likely pathogenic TP53 variants to be within the range of 1 carrier in approximately 4500 individuals [7]; and by the age of $18,41 \%$ of patients develop tumor [2].

The most common female cancer in general population is $\mathrm{BC}$ but the mutation frequencies are relatively low in different populations. Most common is the hereditary breast and ovarian cancer syndrome caused by germline mutation in $B R C A 1 / 2$ genes, accounting for about $5 \%$ of BCs $[8,9]$. Germline mutations in TP53 causing LFS are very rare and account for less than $1 \%$ of $\mathrm{BC}$ cases $[10,11]$. On the other hand, STSs are less common heterogeneous group of malignant neoplasms derived from cells of mesodermal origin and only the minority of STSs are associated with inherited syndromes such as LFS [12]. Solitary fibrous tumor (SFT) is a rare type of sarcoma of fibroblastic origin comprising a histologic spectrum of rarely metastasizing mesenchymal neoplasms [13]. The majority of SFTs are usually treated by surgery with the 10-year overall survival rate ranging from 54 to $89 \%$ after complete resection of localized disease [14]. The choice of therapy does not significantly differ between sporadic and inherited cases, although some specific features including anatomic location or excessive toxicity may be considered [12].

Two sets of clinical criteria are traditionally used to identify individuals at risk who would benefit from TP53 mutation testing: the Classic criteria proposed in 1988 [1] and the Li-Fraumeni-like syndrome (LFL) criteria with 2 suggested definitions [15, 16]. More recently, Chompret proposed the proband-related criteria independent of family history [17] which were updated in 2015 [2].
In the modern-day era of personalized and precision medicine, there is a growing need for recognition of hereditary predisposition syndromes as it will allow appropriate genetic evaluation and facilitate timely screening, surveillance, and therapy for patients and their relatives. Here, we present the first case of invasive $\mathrm{BC}$ and malignant SFT associated with extremely rare genetic variant of TP53 gene. To this day, there have been two reports of this variant, one classified as uncertain significance, the other as likely pathogenic [18]. Our particular case and its clinical manifestation provide additional arguments for this variant to be considered pathogenic.

\section{Case presentation}

A 36-year-old woman presented with mastalgia and yellowish discharge from her right breast. She reported family history (maternal lineage) positive for cancer. Her mother was diagnosed with $\mathrm{BC}$ at 33 and died, and maternal grandmother at 65 years, also from BC. Uncle who had been a smoker died of lung cancer at the age of 70. She has no other live relatives and siblings and has one 3-year-old son. Radiologic imaging found no suspicious lesions in the breast nor enlarged lymph nodes but showed solitary mediastinal mass which was surgically removed. Patohistological examination revealed fibrous tumor with increased mitotic activity, positive for CD34 and STAT6 by immunohistochemistry staining (Fig. 1). Both tumors/breast cancer and solitary fibrous tumor have stained negative for p53 protein.

No further treatment was indicated and after 4 years of follow-up, a lesion in the upper left quadrant of the right breast was discovered. Needle biopsy suggested a luminal B-like invasive $\mathrm{BC}$ so she underwent mastectomy and axillary dissection. Surgical pathology specimen showed pT1bN1 grade 3 carcinoma (ER 100\%, PR 80\%, Her2 negative, Ki 67 26.5\%, micrometastasis in 1 out of 11 lymph nodes).

Four cycles of adjuvant treatment with doxorubicin and cyclophosphamide was administered followed by radiotherapy and tamoxifen with ovarian function suppression. The testing for $B R C A 1 / 2$ was carried out and found no mutations.

One year later, during preoperative evaluation for breast reconstruction surgery, 4 pulmonary nodular lesions were discovered on chest computed tomography (CT) scan. A CT-guided biopsy of one of the suspected metastases was performed and pathohistological examination was consistent with metastasis of malignant fibrous tumor. Tamoxifen was switched to exemestane due to its possible proliferative effect on fibrous tumor. Chemotherapy for stage IV sarcoma with temozolomide and bevacizumab was initiated given the prior anthracycline chemotherapy. 


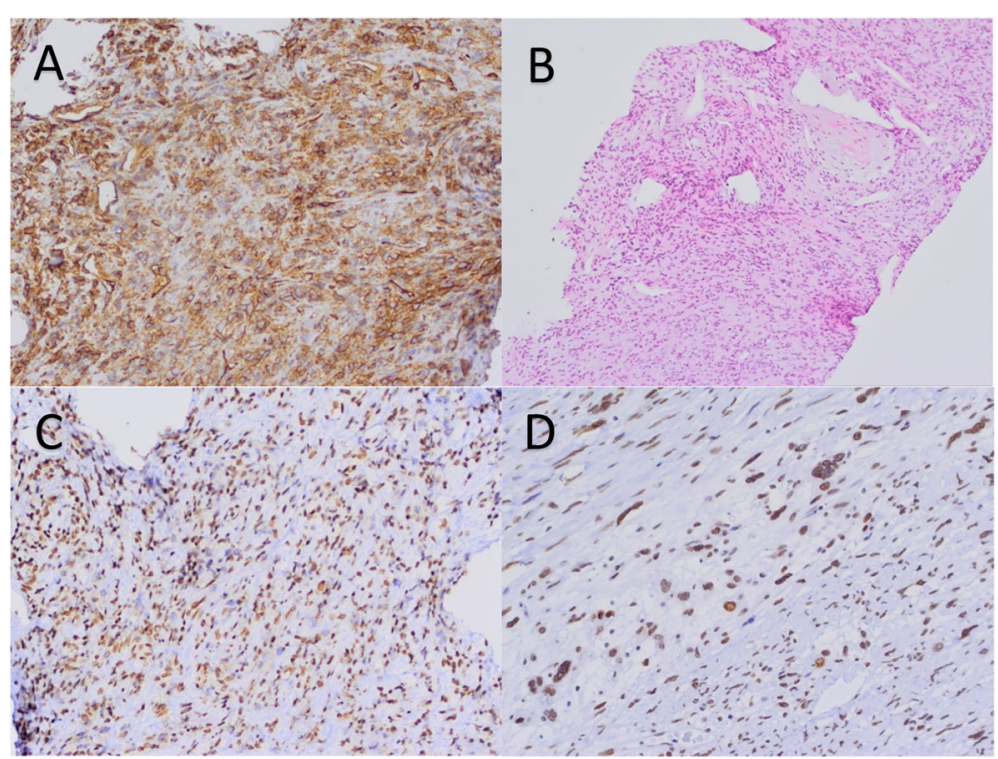

Fig. 1 Histopathological analyses of solitary fibrous tumor tissue. A Immunohistochemical staining of CD34, typical positive staining on solitary fibrous tumor. B Hemalaun-eosin staining of core biopsy tumor tissue from pulmonary metastasis of primary fibrous tumor. C Immunohistochemical staining for STAT6 on solitary fibrous tumor (positive nuclear staining, low magnification). D Immunohistochemical staining for STAT6 on solitary fibrous tumor (positive nuclear staining, high magnification)

In the light of the two known malignancies, the patient was referred to genetic counseling and in contrast to prior $B R C A 1 / 2$ gene testing only, the multigene panel testing was performed. For the testing purposes, DNA was isolated from peripheral blood using TruSight Rapid Capture commercial reagent kit (Illumina Inc.). DNA sequencing was conducted on a MiSeq sequencing platform (Illumina Inc.) with obtained data analyzed using the Variant Interpreter software (Illumina Inc.) and by searching the OMIM, ClinVar, HGMD, dbSNP, COSMIC, gnomAD, and 1000 Genomes databases. The above methods confirmed a germline single nucleotide variant: (c.1101-1G>A) in TP53 gene. She was found to be heterozygous for single nucleotide variant (c.1101$1 \mathrm{G}>\mathrm{A}$ ) affecting the acceptor splice site at intron 10 in TP53 gene, consistent with LFS. This sequence is submitted to ClinVar database, accession number SCV001161439. There were no live siblings for additional germline testing and a 3-year-old son is not permitted for testing without father's permission according to Croatian laws.

In order to gain additional insight into the genetic and molecular profile of the tumor, a comprehensive genomic profiling (CGP) by a hybrid capture-based DNA sequencing platform was done from tumor tissue obtained from one of the pulmonary metastases. CGP performed by Foundation Medicine, Inc. identified two TP53 short variant events: Y163N at $19.4 \%$ allele frequency and splice site $1101-1 \mathrm{G}>\mathrm{A}$ at $62.1 \%$ allele frequency. The report also revealed a microsatellite stable tumor harboring a relatively low mutational burden of 7 Muts/Mb associated with lower rates of clinical benefit from treatment with PD-1- or PD-L1-targeting immune checkpoint inhibitors $[19,20]$. Furthermore, additional mutations in PTCH1 (subclonal), PDGFRB, and the NAB2-STAT6 fusion were confirmed as a somatic event in tumor tissue, none of which have reported therapeutic options with clinical benefit in patient's tumor type. The list of genes tested has provided in the Supplementary materials.

\section{Discussion and conclusions}

Tumor suppressor protein p53 plays an important role in regulating the cell metabolism and as the key tumor suppressor is mutated in over half of all human cancer [21]. One study suggested TP53 as independent negative prognostic marker in breast cancer, although this can be debated as the responses to treatment with anthracyclines range from complete remission to progressive disease [22]. According to the International Agency for Research on Cancer Database, 437 variants of TP53 have been identified to date [23].

Our patient had a relatively high age of onset of first malignancy associated with LFS. Average age for diagnosis of LFS-related cancer in women is 28 years, and even lower when breast cancers in female mutation carriers are excluded [2].

LFS-related BCs are predominantly positive for hormone receptors (84\%) and/or HER2/neu (63\% of the invasive $\mathrm{BCs}$ and $73 \%$ of in situ BCs) [3, 24]. Newer study 
proposes that American College of Medical Genetics and Genomics/Association for Molecular Pathology (ACMG/AMP) TP53-specific PP4 criterion includes identification of HER2+ status for BC diagnosed before the age of 40 in addition to PS4 for clinical criteria if the specific clinical criteria are met [25].

Mastectomy is recommended rather than lumpectomy in order to reduce the risks of a second primary BC and avoid radiation due to the possibility of inducing secondary cancer $[3,26]$. Considering the increased risk of late toxicity and secondary malignancy from cytotoxic treatments in individuals who carry TP53 mutation, targeted biological agents seem to be a safer therapeutic option [27]. Furthermore, the patient had adjuvant estrogen receptor modulation therapy replaced with aromatase inhibitor plus ovarial suppression with goserelin as tamoxifen has been associated with increased risk of uterine sarcoma [28].

Next to BC, STSs are the most common malignancy associated with LFS [2], and SFT is by itself a rare tumor of unknown etiology that accounts for $2 \%$ of soft tissue tumors [29]. Even though it may be found anywhere in the body, the majority are intra-thoracic with $50-80 \%$ being discovered incidentally on chest imaging as asymptomatic masses [29]. Given that SFT is a rare tumor, there are no established guidelines for management and complete surgical resection has remained the mainstay of treatment with low rates of local recurrence as well as progression to metastatic disease [14]. Malignant variant of SFT are, on the other hand, far more likely to recur [29]. Furthermore, inclusion of molecular factors such as TP53 and TERT promoter status may be prognostic indicators considering tumors with these mutations are classified as high risk and patients almost always develop metastases and die [30]. There is no standard chemotherapy for malignant SFT and the combination of temozolomide and bevacizumab appears the most promising with partial response seen in $79 \%$ of cases [14].

When LFS is suspected, different sets of clinical criteria are used and the combination of Chompret's and Classic achieves highest level of sensitivity [2, 22]. In our case, only 2 out of 3 of the Classic LFS criteria were positive. These include proband diagnosed with sarcoma before the age of 45 , first-degree relative with a cancer diagnosis before the age of 45 , and another first- or second-degree relative with cancer diagnosis before the age of 45 or sarcoma at any age [1]. However, she did meet the Chompret's second criterion which refers to proband having multiple primary tumors (except multiple breast tumors), two of which belong to the LFS tumor spectrum, with the initial cancer occurring before the age of 46 years $[2,17]$. Hence, the patient was referred to genetic counseling and testing. This is to our knowledge the first report of single nucleotide variant
(c.1101-1G>A) in TP53 gene manifesting as invasive BC and malignant SFT in woman with positive familial history. The detected variant is a rare germline TP53 variant affecting the acceptor splice site at intron 10 with conflicting interpretations of pathogenicity according to ClinVar and UMD TP53 databases [18, 31, 32]. Prior documented cases in ClinVar include one classified as uncertain significance and the other as likely pathogenic, from 2016 to 2017, respectively [18]. Recognition of this variant as likely pathogenic is based on one affected individual with childhood adrenocortical tumor without relatives with Li-Fraumeni-component tumors [31]. There were no other live relatives or siblings in this family for germline testing for this variant. Her 3-year-old son will be tested for germline variant as soon as his father gives a consent on testing (according to Croatian law genetic testing of minors is allowed with both parents consenting as they are divorced).

Functional loss of tumor suppressor protein encoded by TP53 is common for more aggressive cancers [33]. And, as stated in the CGP report, two alterations of TP53 gene are found in tumor, both have been functionally characterized as inactivating and/or result in the disruption or partial or complete loss of the region encoding the TP53 DNA-binding domain (Y163N) or the tetramerization domain (splice site 1101-1G>A) such as observed here, are thought to dysregulate the transactivation of p53-dependent genes and are predicted to promote tumorigenesis [34-36]. According to data on histopathologic features of breast cancer in Li-Fraumeni syndrome published recently, IHC staining of p53 protein depends on type of mutation. High p53 IHC expression was seen in tumors from individuals with germline TP53 missense mutations, whereas little or no protein expression $(<1 \%$ nuclear expression, null pattern) was seen in tumors from carriers of non-missense mutations [37]. In our patient, there were no p53 IHC expressions either on sarcoma tissue or breast carcinoma tissue.

Initially, our patient was tested for $B R C A 1 / 2$ mutations with no prior genetic counseling. Indeed, the majority of germline mutations in patients with $\mathrm{BC}$ will be in the $B R C A$ genes, albeit a small proportion of families may be in the TP53 or PTEN genes in relation to LFS or Cowden's syndrome, respectively [7, 8]. An earlier diagnosis of LFS would have influenced the treatment if the patient had been referred for counseling at the time of the first tumor occurrence.

In conclusion, this article reports a never before documented clinical manifestation of a rare TP53 genetic variant in an individual with two primary malignancies. Taking into account the presented information and following ACMG criteria, we believe that this variant should be considered pathogenic. Furthermore, the 
report highlights the potential benefits of early genetic testing of the populations at risk.

\section{Supplementary Information}

The online version contains supplementary material available at https://doi. org/10.1186/s12957-021-02370-8

Additional file 1. List of genes.

\section{Acknowledgements}

Not applicable.

\section{Authors' contributions}

JP conducted a literature search and drafted with the manuscript. KGJ and FB have conducted gene sequencing analyses; KGJ and FB contributed to the manuscript review. JP and NDP wrote the final version of the manuscript. All authors reviewed and approved the final manuscript.

\section{Funding}

This research did not receive any specific grant from funding agencies in the public, commercial, or not-for-profit sectors.

\section{Availability of data and materials}

All the data are available in the patient's medical record.

\section{Declarations}

Ethics approval and consent to participate

Not applicable, the need for approval was waived. Consent was obtained from the patient for participation in this study in May 2020

\section{Consent for publication}

We obtained the patient's consent for publication of this case report in May 2020.

\section{Competing interests}

The authors have no competing interests relevant to this article.

\section{Author details}

${ }^{1}$ Department of Oncology, University Hospital Centre Zagreb, Kišpatićeva 12, 10000 Zagreb, Croatia. ${ }^{2}$ School of Dental Medicine, University of Zagreb, Gundulićeva 5, 10000 Zagreb, Croatia. ${ }^{3}$ School of Medicine, University of Zagreb, Šalata 3, 10000 Zagreb, Croatia. ${ }^{4}$ Department of Neurology, University Hospital Centre Zagreb, Kišpatićeva 12, 10000 Zagreb, Croatia. ${ }^{5}$ Center for Translational and Clinical Research, Department for Functional Genomics, School of Medicine, University Hospital Centre Zagreb, University of Zagreb, Šalata 2, 10000 Zagreb, Croatia.

Received: 20 April 2021 Accepted: 12 August 2021

Published online: 27 August 2021

\section{References}

1. Li FP, Fraumeni JF Jr, Mulvihill JJ, et al. A cancer family syndrome in twentyfour kindreds. Cancer Res. 1988;48(18):5358-62.

2. Bougeard G, Renaux-Petel M, Flaman JM, Charbonnier C, Fermey P, Belotti $M$, et al. Revisiting Li-Fraumeni syndrome from TP53 mutation carriers. J Clin Oncol. 2015;33(21):2345-52. https://doi.org/10.1200/JCO.2014.59.5728.

3. Malkin D. Li-Fraumeni syndrome. Genes Cancer. 2011;2(4):475-84. https:// doi.org/10.1177/1947601911413466.

4. Damieni S, Rao VR, Kumar S, et al. Germline mutations of TP53 gene in breast cancer. Tumour Biol. 2014;35(9):9219-27. https://doi.org/10.1007/s132 77-014-2176-6.

5. Lane DP, Crawford LV. T antigen is bound to a host protein in SV40 transformed cells. Nature. 1979;278(5701):261-3. https://doi.org/10.1038/2 $78261 \mathrm{a0}$.

6. Chompret $\mathrm{A}$, Brugieres $\mathrm{L}$, Ronsin $\mathrm{M}$, et al. P53 germline mutations in childhood cancers and cancer risk for carrier individuals. Br J Cancer. 2000; 82(12):1932-7. https://doi.org/10.1054/bjoc.2000.1167.
7. de Andrade KC, Frone MN, Wegman-Ostrosky T, Khincha PP, Kim J, Amadou A, et al. Variable population prevalence estimates of germline TP53 variants: a gnomAD-based analysis. Hum Mutat. 2019;40(1):97-105. https://doi.org/1 $0.1002 /$ humu.23673.

8. Fackenthal JD, Olopade OI. Breast cancer risk associated with BRCA1 and BRCA2 in diverse populations. Nat Rev Cancer. 2007;7(12):937-48. https:// doi.org/10.1038/nrc2054

9. Malone KE, Daling JR, Doody DR, Hsu L, Bernstein L, Coates RJ, et al. Prevalence and predictors of BRCA1 and BRCA2 mutations in a populationbased study of breast cancer in white and black American women ages 35 to 64 years. Cancer Res. 2006;66(16):8297-308. https://doi.org/10.1158/00085472.CAN-06-0503.

10. Evans DG, Birch JM, Thorneycroft M, McGown G, Lalloo F, Varley JM. Low rate of TP53 germline mutations in breast cancer/sarcoma families not fulfilling classical criteria for Li-Fraumeni syndrome. J Med Genet. 2002; 39(12):941-4. https://doi.org/10.1136/jmg.39.12.941.

11. Borresen AL, Andersen TI, Garber J, et al. Screening for germline TP53 mutations in breast cancer patients. Cancer Res. 1992;52(11):3234-6.

12. Farid M, Ngeow J. Sarcomas associated with genetic cancer predisposition syndromes: a review. Oncologist. 2016;21(8):1002-13. https://doi.org/10.1 634/theoncologist.2016-0079.

13. Davanzo B, Emerson RE, Lisy M, Koniaris LG, Kays JK. Solitary fibrous tumor Transl Gastroenterol Hepatol. 2018;3:94. https://doi.org/10.21037/tgh.2018.11. 02.

14. Park MS, Patel SR, Ludwig JA, Trent JC, Conrad CA, Lazar AJ, et al. Activity of temozolomide and bevacizumab in the treatment of locally advanced, recurrent, and metastatic hemangiopericytoma and malignant solitary fibrous tumors. Cancer. 2011;117(21):4939-47. https://doi.org/10.1002/cncr.2 6098

15. Birch JM, Hartley AL, Tricker KJ, Prosser J, Condie A, Kelsey AM, et al. Prevalence and diversity of constitutional mutations in the p53 gene among 21 Li-Fraumeni families. Cancer Res. 1994;54(5):1298-304.

16. Eeles RA. Germline mutations in the TP53 gene. Cancer Surv. 1995;25:10124.

17. Tinat J, Bougeard G, Baert-Desurmont S, Vasseur S, Martin C, Bouvignies E, et al. 2009 version of the Chompret criteria for Li Fraumeni syndrome. J Clin Oncol. 2009;27(26):e108-e9. https://doi.org/10.1200/JCO.2009.22.7967.

18. National Center for Biotechnology Information. ClinVar [VCV000231146.1] [Internet]. 2020 [cited 2020 Feb 16]. Available from: https://www.ncbi.nlm. nih.gov/clinvar/variation/NCV000231146.1.

19. Goodman AM, Kato S, Bazhenova L, Patel SP, Frampton GM, Miller $V$, et al. Tumor mutational burden as an independent predictor of response to immunotherapy in diverse cancers. Mol Cancer Ther. 2017;16(11):2598-608. https://doi.org/10.1158/1535-7163.MCT-17-0386.

20. Goodman AM, Sokol ES, Frampton GM, Lippman SM, Kurzrock R. Microsatellite-stable tumors with high mutational burden benefit from immunotherapy. Cancer Immunol Res. 2019;7(10):1570-3. https://doi.org/1 0.1158/2326-6066.CIR-19-0149.

21. Liu J, Zhang C, Hu W, Feng Z. Tumor suppressor p53 and metabolism. J Mol Cell Biol. 2019;11(4):284-92. https://doi.org/10.1093/jmcb/mjy070.

22. Gonzalez KD, Noltner KA, Buzin CH, Gu D, Wen-Fong CY, Nguyen VQ, et al. Beyond Li Fraumeni syndrome: clinical characteristics of families with p53 germline mutations. J Clin Oncol. 2009;27(8):1250-6. https://doi.org/10.1200/ JCO.2008.16.6959

23. Bouaoun L, Sonkin D, Ardin M, et al. TP53 Variations in human cancers: new lessons from the IARC TP53 database and genomics data. Hum Mutat. 2016; 37(9):865-76. Ver R20, July 2019. https://doi.org/10.1002/humu.23035.

24. Masciari S, Dillon DA, Rath M, Robson M, Weitzel JN, Balmana J, et al. Breast cancer phenotype in women with TP53 germline mutations: a Li-Fraumeni syndrome consortium effort. Breast Cancer Res Treat. 2012;133(3):1125-30. https://doi.org/10.1007/s10549-012-1993-9.

25. Fortuno C, Mester J, Pesaran T, Weitzel JN, Dolinsky J, Yussuf A, et al. LiFraumeni Exploration (LIFE) Consortium, James PA, Spurdle AB. Suggested application of HER2 + breast tumor phenotype for germline TP53 variant classification within ACMG/AMP guidelines. Hum Mutat. 2020;41(9):1555-62. https://doi.org/10.1002/humu.24060.

26. Evans DG, Birch JM, Ramsden RT, Sharif S, Baser ME. Malignant transformation and new primary tumours after therapeutic radiation for benign disease: substantial risks in certain tumour prone syndromes. J Med Genet. 2006:43(4):289-94. https://doi.org/10.1136/jmg.2005.036319. 
27. Packwood K, Martland G, Sommerlad M, Shaw E, Moutasim K, Thomas G, et al. Breast cancer in patients with germline TP53 pathogenic variants have typical tumour characteristics: the cohort study of TP53 carrier early onset breast cancer (COPE study). J Pathol Clin Res. 2019;5(3):189-98. https://doi. org/10.1002/cjp2.133.

28. Gottlieb S. Tamoxifen may increase risk of uterine sarcoma. BMJ. 2002; 325(7354):7. https://doi.org/10.1136/bmj.325.7354.7/a.

29. Robinson LA. Solitary fibrous tumor of the pleura. Cancer Control. 2006; 13(4):264-9. https://doi.org/10.1177/107327480601300403.

30. Machado I, Morales GN, Cruz J, Lavernia J, Giner F, Navarro S, et al. Solitary fibrous tumor: a case series identifying pathological adverse factorsimplications for risk stratification and classification. Virchows Arch. 2020; 476(4):597-607. https://doi.org/10.1007/s00428-019-02660-3.

31. Pinto EM, Ribeiro RC, Kletter GB, Lawrence JP, Jenkins JJ, Wang J, et al. Inherited germline TP53 mutation encodes a protein with an aberrant Cterminal motif in a case of pediatric adrenocortical tumor. Fam Cancer. 2011;10(1):141-6. https://doi.org/10.1007/s10689-010-9392-z.

32. UMD TP53 Mutation Database [Internet]. [cited 2019 Aug 30] Available from: https://p53.fr/tp53-database.

33. Brown CJ, Lain S, Verma CS, Fersht AR, Lane DP. Awakening guardian angels: drugging the p53 pathway. Nat Rev Cancer. 2009;9(12):862-73. https://doi.org/10.1038/nrc2763.

34. Joerger AC, Fersht AR. Structural biology of the tumor suppressor p53. Annu Rev Biochem. 2008;77(1):557-82. https://doi.org/10.1146/annurev.biochem. 77.060806.091238.

35. Kato S, Han SY, Liu W, Otsuka K, Shibata H, Kanamaru R, et al. Understanding the function-structure and function-mutation relationships of p53 tumor suppressor protein by high-resolution missense mutation analysis. Proc Natl Acad Sci U S A. 2003;100(14):8424-9. https://doi.org/10.1 073/pnas.1431692100.

36. Zerdoumi Y, Lanos R, Raad S, et al. Germline TP53 mutations result into a constitutive defect of p53 DNA binding and transcriptional response to DNA damage. Hum Mol Genet. 2017;26(14):2812. https://doi.org/10.1093/ hmg/ddx165. Erratum for: Hum Mol Genet. 2017;26 (14): 2591-2602.

37. Kuba MG, Lester SC, Bowman T, Stokes SM, Taneja KL, Garber JE, et al. Histopathologic features of breast cancer in Li-Fraumeni syndrome. Mod Pathol. 2021;34(3):542-8. https://doi.org/10.1038/s41379-020-0610-4 Epub 2020 Jul 7. PMID: 32636452.

\section{Publisher's Note}

Springer Nature remains neutral with regard to jurisdictional claims in published maps and institutional affiliations.

Ready to submit your research? Choose BMC and benefit from:

- fast, convenient online submission

- thorough peer review by experienced researchers in your field

- rapid publication on acceptance

- support for research data, including large and complex data types

- gold Open Access which fosters wider collaboration and increased citations

- maximum visibility for your research: over $100 \mathrm{M}$ website views per year

At BMC, research is always in progress.

Learn more biomedcentral.com/submissions 